\title{
População em situação de rua e a pandemia da Covid-19 no Brasil
}

Homeless population and the Covid-19 pandemic in Brazil

\section{Alda Maria Lacerda da Costa (Orientadora) \\ alda.lacerda@fiocruz.br}

Doutora em Saúde Pública pela Escola

Nacional de Saúde Pública Sergio Arouca

(ENSP) - Fiocruz (2010).

\section{Caio dos Santos Araújo \\ caiosantod@hotmail.com}

Mestrando pelo programa de Pós Graduação em Ciências Sociais (PPGCIS) PUC Rio.

\section{Resumo}

$\mathrm{O}$ artigo trata das violações dos direitos humanos das pessoas em situação de rua durante a pandemia da Covid-19 no Brasil. O trabalho é baseado em uma análise qualitativa feita a partir do levantamento dos dados referentes à estimativa e perfil das pessoas em situação de rua no Brasil. Estuda-se os dados em diálogo com a discussão conceitual do funcionamento do biopoder e da necropolítica durante um contexto pandêmico.

Palavras-chave: Direitos humanos; pessoas em situação de rua; pesquisa qualitativa.

\begin{abstract}
This article proposes to address the human right violations of homeless people during the covid19 pandemic in Brazil. The work is based on a qualitative analysis based on a survey of data regarding the estimate and profile of homeless people in Brazil. The data is studied in dialogue with a conceptual discussion of the functioning of biopower and necropolitics during a pandemic context.
\end{abstract}

Keywords: Human rights; homeless people; qualitative research. 
ARAÚJO, Caio dos santos; COSTA, Alda Maria Lacerda da. População em situação de rua e a pandemia do

\section{Introdução}

Este artigo discute o crescente número das pessoas em situação de rua (PSR) nas grandes capitais do país e como esse cenário se agravou durante a pandemia da Covid-19. Baseia-se na análise qualitativa e se divide em dois momentos. $\mathrm{O}$ primeiro inclui os dados referentes à estimativa e perfil da PSR no Brasil. A discussão conceitual, em um segundo momento, auxilia na formulação dos fundamentos teórico-metodológicos da pesquisa para melhor compreensão dos desafios que a pandemia da Covid-19 impôs, tal como, as violações dos direitos humanos sociais, que expõem os bloqueios estruturais e institucionais que impedem a distribuição equitativa por meio do funcionamento do biopoder e da necropolítica.

Dentre alguns direitos previstos na Declaração dos Direitos Humanos de 1948 que tiveram reconhecimento no âmbito nacional com a Emenda Constitucional número 26 de 2000 - segundo a qual o Estado tem responsabilidades diante dos direitos sociais - estão educação, a saúde, o trabalho, a moradia, o lazer, a segurança (Brasil, 2000). A declaração dos direitos do homem de 1948 passa por uma dialética - ao universalizar a abstrata noção dos direitos naturais, este se particulariza nas múltiplas realidades concretas positivando-o (Bobbio, 2004, p.16). Ao falarmos sobre o tema da moradia enquanto um direito fundamental do indivíduo, se sabe do aumento do número de pessoas em situação de rua nas grandes cidades brasileiras. Esse fenômeno deve ser compreendido dentro de uma perspectiva social, econômica e cultural. As pessoas em situação de rua constituem um grupo heterogêneo muitas vezes, possuem em comum a situação de vulnerabilidade, e na área da saúde complicações como: tuberculose, doenças sexualmente transmissíveis, o uso prejudicial de drogas; problemas de saúde mental e manifestações de sofrimento físico e psíquico (Brasil, 2013).

Embora a ligação entre o uso de drogas e a condição de rua não se constitua uma relação direta, é elevado o número de pessoas em situação de rua que possuem experiência com drogas, como álcool e crack. Os locais de uso, popularmente conhecidos como "cracolândias" concentram muitos usuários nos centros urbanos do país. Segundo Assumpção (2016), o mapeamento de 2011 concluiu que em Manguinhos (RJ) existiam 16 cenários de uso, sendo o maior deles com variação entre 150 a 300 pessoas.

$\mathrm{Na}$ "Pesquisa Nacional sobre o uso de crack", Bastos e Bertoni (2014) apontaram que o perfil dos usuários em situação de rua são jovens adultos, em sua maioria, negros ou pardos e com baixa escolaridade. A estimava, em março de 2020, era que 221.869 pessoas se encontravam em situação de rua no Brasil, sendo a região Sudeste $(56,2 \%)$ com maior 
percentual, seguida pelo Nordeste $(17,2 \%)$. O aumento do número de pessoas em situação de rua entre o período de setembro de 2012 a março de 2020 chegou a $140 \%$ :

O crescimento é observado em todas as Grandes Regiões e em municípios de todos os portes, o que sugere ser o mesmo efeito de dinâmicas nacionais. Por sua vez, o crescimento mais intenso nos grandes municípios sugere que a crise econômica e em particular o aumento do desemprego e da pobreza sejam fatores importantes para a explicação do ocorrido. (Silva; Natalino; Pinheiro, 2020, p.12)

Estes dados expõem a vulnerabilidade estrutural em que se encontram as pessoas em situação de rua e coloca em xeque algumas dificuldades de acesso ao Sistema Único de Saúde (SUS), em um primeiro momento, devido à ausência de documentação ou domicílio cadastrado. O bloqueio burocrático, por exemplo, tendo por fundamento a vinculação à residência física, ou mesmo, documento de identificação, exclui do SUS as pessoas em situação de rua. Por não se encontrar dentro do padrão normativo a ser assistido - a categoria "ser de rua" reflete um estigma compartilhado pelas instituições frente a um tipo específico de cidadão, muitas vezes, maltrapilho ou "sujo" - sua condição exclui a possibilidade de atendimento.

Como narra Assumpção (2016), mesmo com agendamento feito para atendimento em um instituto de traumatologia e ortopedia, seguindo todos os trâmites formais, e sendo o usuário acompanhado pela equipe do consultório na rua, ele não foi atendido devido à falta de documento de identificação. Os hospitais públicos, porém, como é sabido, possuem, pelo menos em princípio, a universalidade do atendimento público de saúde. Pode-se pontuar, portanto, a situação de invisibilidade do grupo perante o Estado e a violação de direitos humanos fundamentais - à moradia e à saúde.

\section{Pandemia, luta de classes e racismo}

O debate acerca do estigma, por exemplo, postulado por Erwing Goffman (1975) nos possibilita compreender como este acaba por operar como um dispositivo de poder que acaba por bloquear o acesso ao serviço público de saúde. Ao propor a existência de uma identidade virtual, sinaliza uma discrepância entre a identidade social virtual (o caráter que imputamos ao indivíduo) e a sua identidade social real (os atributos que o indivíduo possui na realidade).

Tal característica é um estigma especialmente quando seu efeito de descrédito é muito grande - algumas vezes ele também é considerado um defeito, uma fraqueza, uma desvantagem - e constitui uma discrepância específica entre identidade social virtual e a identidade social real. (Goffman, 1975, p.11) 
Goffman relata três tipos de estigma: 1. as abominações do corpo; 2. As culpas de caráter individual e 3. os estigmas de raça, nação e religião, e acrescenta que:

Por definição, acreditamos que alguém com um estigma não seja completamente humano. Com base nisso fazemos vários tipos de discriminações, através das quais efetivamente, e muitas vezes sem pensar, reduzimos suas chances de vida. (Goffman, 1975, p.15)

Torna-se pertinente, neste sentindo, como expõe o antropólogo Richard Parker em seu trabalho "Estigma, discriminação e Aids" (Parker, Aggleton, 2001), a aproximação de Goffman com o trabalho de Michel Foucault para que se possa articular a complementaridade das questões levantadas pelos autores. Segundo Parker, ao lermos os autores em paralelo chegamos às estigmatizações enraizadas na história e na cultura, pautada na desvalorização daquilo que foge às normas. Daí deriva a ideia de "violência estrutural" do autor. Para além do bloqueio burocrático imposto às pessoas em situação de rua devido à ausência de documentação, existem outras práticas não prescritas que impedem a assistência universal do SUS.

A discussão acerca do biopoder e do Estado de Exceção apresentada por Foucault sinaliza o poder soberano e seu funcionamento do "fazer morrer e deixar viver", ou seja, o gerenciamento da vida e da morte. A possibilidade de decidir quem merece permanecer vivendo, na modernidade, emerge como uma forma de incidência do poder sobre a vida, que ele definiu como biopolítica. A biopolítica emerge quando a vida natural é incluída, por meio dos fenômenos da saúde, nos cálculos do poder estatal e passa a ser assistida por mecanismos de governo. Para o autor, existem duas tomadas de poder - a primeira tomada é sobre o corpo e é individualizante, o poder disciplinar, e a segunda se volta ao domínio do homem enquanto espécie, sendo esta massificante. Dessa forma, a tomada do poder sobre a vida se dá por meio do controle dos processos de nascimento, morte, doença, produção etc (Foucault, 2010, p.20721).

As epidemias da idade média eram temidas pelo perigo da "morte iminente", "da morte multiplicada" (Foucault, 2010, p.205) Pode-se perceber que, hoje, o conhecimento sobre as endemias, epidemias busca controlar as doenças que geram instabilidade, é preciso maximizar o tempo de vida de população. A biopolítica lida com a questão das massas, da população enquanto um problema científico e político, compreendendo que os fenômenos compartilhados coletivamente possuem efeitos políticos e econômicos. Estes fenômenos, segundo Foucault, podem ser aleatórios e imprevisíveis, como o surgimento de um vírus altamente contagioso. $\mathrm{O}$ 
ARAÚJO, Caio dos santos; COSTA, Alda Maria Lacerda da. População em situação de rua e a pandemia do

controle político se dá em todas as esferas da vida humana, já que, a reprodução da biopolítica e seu domínio estatístico almejam a estabilidade, e na possibilidade, a previsibilidade.

A noção de biopoder formulada por Foucault divide aqueles que devem viver e os que devem morrer. Esta divisão se torna possível mediante a segmentação da população em grupo e o estabelecimento da censura biológica para uns em detrimento de outros. Essa é a definição que Foucault dá ao racismo. Desse modo, o racismo é a tecnologia empreendida a permitir o funcionamento do biopoder entendido como o direito do soberano sobre a morte, abrindo possibilidade às funções assassinas do Estado. De outra maneira, além de poder expor a morte, o Estado detém o direito da espada, o direito de matar.

Esta configuração pode ser encontrada dentro da instituição escravocrata no Brasil, pautada na vinda forçada de negros escravizados, que mobilizou as esferas pública e privada ambas "contaminadas" por práticas alinhadas à produção da morte (material e simbólica), mesmo que legitimada sob manto da modernidade e promoção da vida (Flauzina, 2006). A população negra escravizada no Brasil, mesmo após a abolição, não assistiu e/ou participou de um movimento pós-abolicionista que pudesse levar a novos pilares democráticos, pelo contrário. Em 1890, dois anos após a assinatura da Lei Áurea, a prática de mendicância e da capoeira são criminalizadas. A medida é adotada em um contexto em que maioria da população brasileira é formada por negros libertos que, ao saírem das senzalas, foram ocupar as ruas e as periferias dos principais centros urbanos (Rolnik, 1989, p.1-17).

A tentativa de reconstituir historicamente o contexto da população em situação de rua no Brasil, em específico no estado do Rio de Janeiro, se torna primordial para o entendimento desse fenômeno nas grandes metrópoles. No caso do Rio de Janeiro, temos historicamente um processo de ocupação da terra que se deu dentro de uma lógica de crescimento desordenado e de exclusão. $\mathrm{O}$ acesso não equitativo à terra, no Rio de Janeiro, em particular, se revela como parte de um projeto que deixa a maioria de população sem direitos à moradia. Dentro de um espectro histórico, algumas práticas, como coloca Achille Mbembe, em Necropolítica (2018), são resquícios de uma prática colonial que adotou a raça como determinante hierárquico. Dentre essas práticas, se pode citar: restrições na produção de áreas para negros em áreas brancas, restrição à posse de terras, exceto em territórios reservados, criminalização de territórios com maioria negra e controle do fluxo.

A experiência da colonização faz com que Mbembe (2018) provoque algumas torções ao conceito de Foucault ao propor que a escravidão foi um dos primeiros experimentos da modernidade com base na biopolítica, tal como a própria estrutura do sistema de colonização. Tendo em vista que o escravizado resulta de uma tripla perda - perda de um "lar", perda dos DIGNIDADE RE-VISTA | ISSN2525-698X| 2021 | V. VII | N. 12 | Educação Prática Libertadora - heranças dos 100 anos de Paulo Freire e Dom Paulo Arns. Pastoral Universitária Anchieta PUC-RIO. 
ARAÚJO, Caio dos santos; COSTA, Alda Maria Lacerda da. População em situação de rua e a pandemia do

direitos sob o corpo e do seu status político - pode-se pontuar que não apenas o corpo do escravizado é exposto a uma relação de poder desigual das raças, mas como também o território que vier a ocupar.

\section{Conclusão}

Pode-se questionar, como David Harvey, quem são aqueles capazes de cumprir o isolamento social e aqueles que precisam rompê-lo pela sua sobrevivência e a de sua família (Davis et al., 2020, p.13-24). O "mito" criado sobre a não distinção de classe e/ou raça frente às doenças infecciosas dissimula as condições materiais da precarizada classe trabalhadora que é posta à uma escolha infernal. Desse modo, cabe questionar o impacto da pandemia na vida dos indivíduos entendendo as desigualdades estruturais persistentes em nossa sociedade, tal como seus efeitos sobre os direitos humanos fundamentais, em particular os direitos sociais aqui tratados: à moradia, à saúde, à vida.

Quanto ao contexto da população em situação de rua, não temos a divisão entre casa e rua, como aborda Mbembe (2018), e a tríplice perda os coloca em uma posição de linha de frente. Além das dificuldades estruturais colocadas pela ausência de documentação e pelo racismo, a redução do número de pessoas nas ruas, por conta das medidas de isolamento social, teve grande impacto na vida das PSR. A pessoa em situação de rua, o trabalhador informal ambulante, o "camelô" dependem da circulação de pessoas nas grandes metrópoles para conseguirem garantir sua subsistência. Sem dúvida, o ponto mais fragilizado é o acesso à alimentação, já precária para essa população vulnerável, por meio do chamado "garimpo", que consiste na prática de procurar materiais recicláveis e comida.

O Boletim "De Olho no Corona", em sua décima edição, traz dois relatos de pessoas em situação de rua na região da Maré:

Por causa dessa epidemia do vírus, está difícil até de arrumar uma água pra beber, não tem máscara, não tem álcool em gel. Então a situação está muito difícil ainda pra nós. Depois dessa epidemia ficou um pouco ruim, essa epidemia atrasou o lado do trabalhador, atrasou o lado dos garimpeiros - que também são gente -, dos moradores de rua. Essa epidemia contagiou e ficou difícil pra tudo... pra emprego. Vou tirar por mim mesmo, eu tenho os documentos tudo completo, antes da epidemia tinha uma comunicação legal, depois da epidemia perdi a comunicação de emprego, está difícil de aceitar funcionário. Tudo através dessa pandemia ficou um pouco mais difícil. (2020, p.5) 
O contexto das pessoas em situação de rua reflete um processo de desfiliação do sistema social como pontua Castel (1993). Esses indivíduos, muitas vezes, passam por um processo de ruptura dos vínculos sociais e se encontram à margem do mercado de trabalho formal. "De olho na corona" pontua ainda a invisibilidade do grupo perante as políticas de seguridade social, auxílio emergencial e como essa realidade fica exposta e se agrava com a pandemia da Covid19:

Outro problema social relevante na vida de pessoas que estão em situação de rua é a falta de documentos, requisito necessário para o acesso às políticas da assistência social, como Bolsa Família, Benefício de Prestação Continuada e, no momento, o Auxílio Emergencial. Na amostra realizada pela equipe da Redes da Maré com pessoas que recebem as POPULAÇÃO EM SITUAÇÃO DE RUA, SEGURANÇA ALIMENTAR E ACESSO A DIREITOS NA MARÉ. O ritmo das cidades mudou com as medidas de isolamento social para evitar a disseminação do vírus e isso afetou drasticamente as pessoas que estão em situação de rua. (2020, p.5)

A omissão do governo federal, neste sentido, se apresenta como um projeto que deixa parte significava da sociedade civil abandonada à sua própria sorte. Diante das dificuldades de acesso ao SUS por parcela expressiva da população em situação de rua, o Ministério da Saúde, por meio da Política Nacional de Atenção Básica (Brasil, 2011), preconizou a formação das Equipes do Consultório na Rua (eCR) pautadas na perspectiva da redução de danos para dar conta dessa população específica. As equipes são marcadas pela participação de profissionais de diversas áreas da Atenção Básica e podem ser compostas por médico, enfermeiro, técnico de enfermagem, psicólogo, assistente social e agente social. A finalidade é trabalhar de maneira integrada com a Estratégia Saúde da Família e outros equipamentos sociais e de saúde no território (Brasil, 2011), no sentido de ampliar o acesso aos serviços de saúdes e reduzir as iniquidades. Trata- se de compreender as demandas particulares de cada território, e a pandemia da Covid-19 evidenciou algumas:

(...) vem sofrendo ainda mais durante a pandemia em função da ausência de políticas públicas voltadas às suas necessidades, tais como segurança alimentar, serviços de saúde e acesso a itens de higiene e de proteção à contaminação pelo vírus. (Boletim De Olho no Corona, 2020, p.3).

Contudo, desde 2018, o governo federal tem feito mudanças na Política Nacional de Drogas (Pnad) promovidas pelo líder do executivo Jair Bolsonaro, via decreto $\mathrm{n}^{\circ}$ 9.761, que revoga o documento anterior, assinado em 2002, pelo então presidente Fernando Henrique 
Cardoso. O decreto acompanha mudanças realizadas pelo Conad (Conselho Nacional de Políticas sobre Drogas), que em 2018 já havia implementado modificações, indo ao encontro das práticas de abstinência.

Entre outras medidas, a nova política prevê um modelo de tratamento de usuários de drogas com base na abstinência, retirando alternativas como a redução de danos. O decreto menciona repasses de verbas do Estado para as chamadas "comunidades terapêuticas", entidades privadas para internação temporária de usuários, que costumam ser ligadas a grupos religiosos. Cabe salientar que a medida vai no sentido da criminalização do usuário de drogas e ignora a lógica da redução de danos. Além de deixar de investir nos equipamentos de saúde pública, aumenta a verba para as intuições privadas, predominantemente de cunho religioso. As chamadas comunidades terapêuticas são alvo de sérias denúncias de violações contra os direitos humanos como privação de liberdade e trabalho forçado (Jusbrasil, 2018).

Durante um contexto de pandemia, o gerenciamento da biopolítica se intensifica, e concomitantemente, a reflexão acerca dos efeitos do processo de hierarquização das raças e sua permanência em contextos democráticos sinalizam que as democracias contemporâneas não romperam os limites que a dominação colonial impôs. Subentende-se quais parcelas da população podem ser expostas à morte, ou mesmo morrer. A banalização da morte é um dos efeitos do racismo que estruturou a nossa sociedade, tal a constante deslegitimação do discurso em prol dos direitos humanos. Entende-se os direitos humanos enquanto uma construção, uma meta a ser alcançada, ainda não realizada. Sabe-se, contudo, da capacidade das democracias acumularem contradições e ocultarem sua face brutal e violenta. Desde sua origem, as democracias modernas estão vinculadas à colonização e ao racismo, as democracias de escravos, segundo Mbembe (2017).

Como propunha Fanon (1968), persiste a esfera do inegociável entre "os condenados da terra" e seus "colonos" e isto não ocorre sem uma censura biológica. Segundo Lima (2018), Mbembe aponta que a soberania contemporânea se institui pela normatização do Estado de exceção, que não funciona sem hierarquizar raças. O racismo institucional se constitui, portanto, por diversos componentes que dão suporte à ideia de branquitude, ao mesmo tempo em que o gerenciamento prático dos modos de existência não brancos possibilita aos grupos mais próximos a esse modelo uma estabilidade existencial legitimada pelas instituições, o "perfil do assistido padrão". De outra maneira, se manifesta um certo dispositivo no qual "ter pele branca", "é salvo conduto" (Jesus, 2014, p.55). 


\section{Referências bibliográficas}

ASSUMPÇÃO, Erick Luiz Araújo de. A vida em cenas de uso de crack: ensaio de análise institucional e bioética. Tese de Doutorado. Programa de Pós-graduação em Bioética, Ética Aplicada e Saúde Coletiva. Universidade Federal Fluminense, Niterói, 2016.

BASTOS, Francisco Inácio; BERTONI, Neilani. (Orgs.) Pesquisa Nacional sobre o uso de crack: quem são os usuários de crack e/ou similares do Brasil? Quantos são nas capitais brasileiras? Rio de Janeiro: Editora Icict/Fiocruz, 2014.

BOBBIO, Norberto. A era dos direitos. Rio de Janeiro: Elsevier, 2004.

BRASIL. Constituição da República Federativa do Brasil de 1988. Emenda constitucional No 26 de 2000. Brasília, 14 de fevereiro de 2000. Disponível em: https://www.planalto.gov.br/ccivil_03/constituicao/emendas/emc/emc26.htm Acesso em: 12 set 2020 .

BRASIL. Ministério da Saúde. Secretaria de Atenção à Saúde. Departamento de Atenção Básica. Saúde mental / Ministério da Saúde, Secretaria de Atenção à Saúde, Departamento de Atenção Básica, Departamento de Ações Programáticas Estratégicas. Brasília: Ministério da Saúde, Cadernos de Atenção Básica, n.34, p.58-59, 2013.

BRASIL, 2011. Ministério da Saúde. Portaria n 2488/GM, de 21 de outubro de 2011. Diário Oficial da União 2011; 22 out.

CASTEL, Robert. Da indigência à exclusão, a desfiliação: precariedade do trabalho e vulnerabilidade relacional. In: LANCETTI, A. (Org.) Saúde Loucura 4, Paulo: Hucitec,1993. p.21-44.

DAVIS, Mike et al. Coronavírus e a luta de classes. Brasil: Terra sem Amos, 2020.

FANON, Franz. Os Condenados da Terra. Rio de Janeiro: Civilização Brasileira, 1968.

FLAUZINA, Ana Luiza Pinheiro. Corpo negro caído no chão: o sistema penal e o projeto genocida do Estado brasileiro. 2006. Dissertação de Mestrado. Programa de Pós-graduação em Direito. Universidade de Brasília, Brasília, 2006.

GOFFMAN, E. Estigma: notas sobre a manipulação da identidade deteriorada. Trad. Márcia Bandeira de Mello Leite Nunes Rio de Janeiro: LTC, 1975.

JUSBRASIL. Inspeção nacional aponta graves violações de direitos humanos em comunidades terapêuticas. 2018. Disponível em:

https://mpf.jusbrasil.com.br/noticias/591333084/inspecao-nacional-aponta-graves-violacoesde-direitos-humanos-em-comunidades-terapeuticas. Acesso em: 4 fev 2021.

LIMA, Fátima. Bionecropolítica: diálogos entre Michel Foucault e Achille Mbembe. Arquivos Brasileiros de Psicologia, Rio de Janeiro, v.70, n.spe, p.20-33, 2018.

FOUCAULT, M. Em defesa da sociedade. São Paulo: Martins Fontes, 2010. 
JESUS, C. M. Diário de Bitita. São Paulo: SESI-SP, 2014.

MBEMBE, Achille. Necropolítica. São Paulo: n-1 Edições, 2018.

MBEMBE, Achille. Políticas da inimizade. Trad. Marta Lança. Lisboa: Antígona, 2017.

PARKER, R.; AGGLETON, P. Estigma, Discriminação e Aids. Cidadania e Direitos, Coleção ABIA, Rio de Janeiro, n.1, 2001.

REDES DA MARÉ. Boletim de Olho no Corona, 2020.

ROLNIK, Raquel. Territórios negros nas cidades brasileiras: etnicidade e cidade em São Paulo e Rio de Janeiro. Revista de Estudos Afro-Asiáticos, n.17, p.1-17, 1989.

SILVA, Tatiana Dias; NATALINO, Marco; PINHEIRO, Marina Brito. População em Situação de Rua em Tempos de Pandemia: um Levantamento de Medidas Municipais Emergenciais. Brasília: IPEA, 2020. 